There was no statistically significant difference in MNBI between Barrett's while on or off PPIs $(p=0.556)$. There was also no difference in MNBI between 9 patients with persistent Barrett's who had attempts at ablation therapy compared to the 13 who had not $(p=0.96)$. Using the Kruskall-Wallace test, there was a significant difference observed in MNBI between all 3 categories of reflux $(\mathrm{p}<0.0001)$. Specifically, there was a difference in patients with Barrett's (median MNBI $429.5 \Omega$ $(293 \Omega, 950 \Omega)$ compared to NERD $(1160 \Omega(964.5 \Omega, 2764 \Omega)$ $(\mathrm{p}=0.003)$ and $\mathrm{FH} \quad(3355 \Omega(2866.5 \Omega, 3809.25 \Omega) \quad(\mathrm{p}<0.0001)$. There was also a significant difference in patients with NERD compared to $\mathrm{FH}(\mathrm{p}<0.0001)$.

There was a moderately inverse correlation between Barrett's segment length (median $6 \mathrm{~cm}(3 \mathrm{~cm}, 10 \mathrm{~cm})$ and MNBI $(\mathrm{r}=-0.436 ; \mathrm{p}=0.038)$.

Conclusion In keeping with the published literature, this study shows that severity of reflux disease, as measured by ambulatory $\mathrm{pH}$-impedance monitoring, was not dissimilar between Barrett's oesophagus and NERD, while symptom burden was greater in NERD. On the other hand, MNBI can differentiate between the disease states despite the reduced symptom burden. Also, it correlates with the degree of mucosal damage associated with Barrett's regardless of PPI use or previous therapy. MNBI may be a better marker of reflux disease severity than standard $\mathrm{pH}$ measurements.

\section{PTU-044 VARIATION IN CELL CYCLE MARKERS IN BARRETT'S OESOPHAGUS IN RELATION TO CIRCUMFERENTIAL AND AXIAL LOCATION}

Lance Alleyne*, Danny Cheung, James Rees, Dominic King, Sandra Prew, Ulises Zanetto, Suhail Muzaffar, Mark Anderson, Nigel Trudgill. Sandwell and West Birmingham Hospitals NHS Trust, West Bromwich, UK

\subsection{6/gutjnl-2019-BSGAbstracts.258}

Introduction Reflux oesophagitis and early cancer in Barrett's oesophagus (BO) have been reported to occur more frequently in the 12 to 3 o'clock position at the gastro-oesophageal junction. We analysed markers of proliferation, the cell cycle and inflammation in different circumferential and axial locations in subjects with BO to further study these observations.

Methods A prospective cohort study of adult subjects with BO undergoing endoscopic surveillance between Dec 2013 and July 2016 had quadrantic biopsies taken every $2 \mathrm{~cm}$ of the Barrett's segment, with the circumferential location recorded for the most distal (gastro-oesophageal junction) and proximal biopsies (where 12 o'clock correlates to the gastric lesser curve). Two histopathologists (blinded to biopsy site) reported the degree of expression of various immunohistochemical markers for each biopsy site - p53, Ki67, cyclin D1, COX-2, and $\mathrm{p} 21$. Chi square analysis was performed to identify any association between biopsy site location and the degree of expression of the different cell markers.

Results 112 subjects were included: mean age 62.8 (SD 12.4) years; 78\% male; median Barrett's segment length C4M6, 9.1\% had evidence of dysplasia (6.4\% LGD, 1.8\% HGD, $0.9 \%$ adenocarcinoma).

Expression of Ki67 was found to be highest around the 3 o'clock position and overall was $49.6 \%$ higher in the $12-6$ o'clock areas in the distal biopsies, compared to 6-12 o'clock (odds ratio 1.50 [95\% CI 1.001-2.24]). A similar relationship was found with p21 expression in the 12-6 o'clock biopsies but this fell just short of statistical significance (1.82 [0.96-3.47]).
There was increased expression of most markers in all circumferential locations in the distal biopsies compared to the proximal biopsies - cyclin D1 (1.74 [1.29-2.34]), COX-2 (2.03 [1.48-2.78]) and p21 (2.06 [1.16-3.68]). However, expression of Ki67 was overall higher in the proximal compared to the distal biopsies (1.75 [1.31-2.35]).

Conclusions There is evidence of increased cellular proliferation, as evidenced by Ki67 expression, in the 12-6 o'clock position at the gastro-oesophageal junction. There was also increased expression of cell cycle markers and markers of inflammation at the gastro-oesophageal junction, compared with the top of the Barrett's segment. Since these findings mirror the changes of endoscopic oesophagitis, they suggest that ongoing gastro-oesophageal reflux plays a key role in the development of dysplasia and malignancy in BO.

\section{PTU-045 DOES AGE MATTER? ENDOSCOPIC SUBMUCOSAL DISSECTION (ESD) FOR EARLY BARRETT'S NEOPLASIA}

Sophie Arndtz*, Sharmila Subramaniam, Ejaz Hossain, Mohamed Adbelrahim, Pradeep Bhandari. Queen Alexandra Hospital, Portsmouth, UK

\subsection{6/gutjnl-2019-BSGAbstracts.259}

Aims ESD is an established therapeutic option for the management of early Barrett's neoplasia, offering superior en-bloc and R0 resection rates compared to endoscopic mucosal resection. However, ESD is thought to have a higher complication rate, due to the increased complexity of the procedure. The aim of our study was to evaluate the safety and efficacy of ESD for Barrett's neoplasia in an ageing Western population.

Methods We performed a retrospective analysis of all ESDs conducted for Barrett's neoplasia within a single tertiary referral centre in the UK from 2012-2018. Older patients were defined as $\geq 75$ years of age and younger patients $<75$ years of age at time of procedure.

Results 146 of 316 Barrett's resections were ESDs, of which 51 were $\geq 75$ years and $95<75$ years. Overall age range was 42-94 years and mean follow up was 3.5 years. Average Barrett's length was $5.5 \mathrm{~cm}$ with $16 \%$ of neoplasia occurring in short $(<3 \mathrm{~cm})$ segment Barrett's. Lesion characteristics were similar between the two groups, except increased scarring in $\geq 75$ group (table 1). R0 resection rate was $70.6 \%$ in $\geq 75$ group and $77.9 \%$ in $<75$ group, with only $3.9 \%$ of $\geq 75$ group and $5.3 \%$ of $<75$ group proceeding to surgery or chemoradiotherapy for residual or recurrent neoplasia. Complications occurred in $5.9 \%$ of $\geq 75$ group (1 perforation, 2 bleeds) and $4.2 \%$ of $<75$ group (4 strictures), all of which were endoscopically managed. $3.9 \%$ of $\geq 75$ group and $15.8 \%$ of $<75$ group proceeded to surgery following poor prognostic histology and overall $80.8 \%$ of all patients continued with sole endoscopic management.

$\begin{aligned} & \text { Abstract PTU-045 Table } 1 \\
& \text { 146 ESDs }\end{aligned}$
\begin{tabular}{lllll} 
Age & $\begin{array}{l}\text { Mean age } \\
\text { (years) }\end{array}$ & $\begin{array}{l}\text { Mean lesion } \\
\text { size (mm) }\end{array}$ & $\begin{array}{l}\text { En bloc } \\
\text { resection } \mathbf{n}(\%)\end{array}$ & $\begin{array}{l}\text { Previous resection } \\
\text { (scarring) } \mathbf{n}(\%)\end{array}$ \\
\hline$\geq 75$ & 81 & 31 & $48(94)$ & $16(31)$ \\
$<75$ & 65 & 33 & $90(95)$ & $17(18)$ \\
Total & 70 & 32 & $138(95)$ & $33(23)$ \\
\hline
\end{tabular}

